\title{
THE COOLING EFFECT OF AN URBAN LAKE LANDSCAPE ON THE URBAN HEAT ISLAND: A CASE STUDY IN JINAN, CHINA
}

\author{
YANG, S. J. ${ }^{1,2^{*}}-$ RAN, G. P. ${ }^{3}-$ ZHANG, W. ${ }^{1}-$ WANG, Z. H. ${ }^{2}$ \\ ${ }^{I}$ School of Environment Science and Spatial Informatics, China University of Mining and \\ Technology, China \\ ${ }^{2}$ College of Geography and Environment, Shandong Normal University, Jinan, China \\ ${ }^{3}$ Information and Technology Centre, Jinan meteorological bureau, Jinan, China \\ *Corresponding author \\ e-mail:sdnugps@qq.com
}

(Received 26 ${ }^{\text {th }}$ Sep 2019; accepted 21 ${ }^{\text {st }}$ Jan 2020)

\begin{abstract}
The fact that open water contributes to lowering air temperature is well known in urban landscape planning. Water bodies have been used as tools to reduce the urban heat island effect (UHI). However, the extent to which a water body propagates the cooling effect from the lakeshore is still largely unknown. This study aimed to (1) provide evidence for cooling air temperature on the surrounding urban lakeshore; (2) verify the effect of different land covers surrounding the lakeshore on lowering air temperature; and (3) determine the cooling effects at different distances from the different lakeside areas. Based on urban weather station data and on measured data from Daming lake, Jinan, China, the analytic results reveal significant cooling adjacent to the lakeshore with an average cooling of nearly $1^{\circ} \mathrm{C}$ from July to August. Following the air temperature drop, the cooling effect becomes increasingly weaker, reaching the lowest value of $0.3^{\circ} \mathrm{C}$ in October. Vegetated area causes more of a cooling effect than permeable or impermeable surface. However, the cooling difference between permeable surface and impermeable surface was less significant. At all measuring sites, the cooling level at a horizontal distance of $40 \mathrm{~m}$ from the lakeshore was less than $0.6^{\circ} \mathrm{C}$.
\end{abstract}

Keywords: urbanization, temperature monitoring, water bodies, cooling effect, vegetated landscapes

\section{Introduction}

Over the past twenty years, urbanization and industrialization have been accelerating in developing countries. Although urbanization and industrialization improves the livingstandards of urban inhabitants, these changes bring a series of environmental problems, such as the urban heat island effect, air pollution, and industrial waste (Rizwan et al., 2008; Sun and Chen, 2012; Singh et al., 2017; Li et al., 2018). The urban heat island (UHI) is an increasingly serious problem in many countries. The so-called UHI is simply defined as a metropolitan area that has a warmer near-surface air temperature than its surrounding rural areas (Unwin, 1980; Chang et al., 2007; Su et al., 2012). Aside from the UHI effect on temperature, the UHI has other negative impacts on weather and climate, air pollution, health and welfare, and energy consumption (Rosenfeld et al., 1995).

Water bodies, such as lakes, rivers, ponds, and streams, have the potential to lower surface temperature through continuous evaporation, particularly on sunny days when more water can be absorbed by the air. Each gram of evaporating water absorbs $2500 \mathrm{~J}$ and reduces the surface temperature very effectively (Grinzato et al., 2002). In urban landscape planning and design, water bodies are prominent features. They play the dominant role in urban development as well (Ding and Cao, 2004; Cai et al., 2018; Dai 
et al., 2019). Additionally, urban water bodies are one of the important units of urban ecological systems at the scale of the entire city (Ding and Cao, 2004; Li et al., 2008; Gober et al., 2009; Xu et al., 2010). There have been numerous studies aimed at confirming the effects of water bodies on the UHI in the past few decades, and the data sources to measure urban heat island effect mainly include remotely sensed thermal infrared (TIR) data, in situ data and moving observation data. In recent years, TIR data have been widely employed to retrieve land surface temperature (LST) (Weng, 2009; Guillevic et al., 2014; Li et al., 2014). Sun and Chen (2012) explored the intensity and efficiency of cooling effects of urban water bodies in Beijing city, the LST data were extracted from ASTER images of August 8, 2007, the result showed the mean cooling intensity and efficiency was $0.54{ }^{\circ} \mathrm{C} / \mathrm{hm}$ and $1.76{ }^{\circ} \mathrm{C} / \mathrm{hm} / \mathrm{ha}$, respectively. Gupta et al. (2019) found that average temperature drop of $7.51^{\circ} \mathrm{C}$ and $3.12^{\circ} \mathrm{C}$ is observed during summer and winter, respectively for three years near the Sukhna Lake in Chandigarh city. However, most of the studies on the impacts of rivers on the UHI are confined to the scale of urban river segment. Moreover, the data were collected by conducting an on-site measurement. Murakawa et al. (1991) reported that the drop in the air temperature above the Ota River, Hiroshima, Japan, reached $5^{\circ} \mathrm{C}$ on sunny days in the warmer seasons and that the cooling effect propagated a few hundred meters horizontally and more than eighty meters vertically. Another study based along the River Don, Sheffield, UK, demonstrated that the average cooling effect over the river reached nearly $1{ }^{\circ} \mathrm{C}$ when the ambient temperature exceeded $20^{\circ} \mathrm{C}$ (Hathway and Sharples, 2012). The above studies are based on microclimatic conditions of an urban river. In addition, limited published studies exist on the cooling effect of water bodies at the urban scale. In the desert city of Phoenix, United States, Gober et al. (2009) found that an increasingly irrigated landscaping lowered night-time temperatures in the urban core. Two other studies revealed that the UHI effect was influenced by the surface area of urban water bodies and their geometry (Sun and Chen, 2012; Oláh, 2012). Additionally, in the city of Dongguan, China, research showed that a negative linear relationship exists between water surface area and decreasing ambient temperature at the spatial scale of $500 \mathrm{~m}$ x $500 \mathrm{~m}$ cells (Li et al., 2008). However, an analysis of a network of hobby-meteorological observations in the Netherlands showed that an open water surface area brought a significant increase of the 95 percentile of the UHI (Steeneveld et al., 2014).

Because most studies focusing on the relationship between the UHI and water bodies are limited to a river or a few rivers (Gober et al., 2009; Hathway and Sharples, 2012; Du et al., 2016), the literature on the role of a lake or pond in mitigating the UHI is limited. In comparison to a river, the different effect of a lake on mitigating the UHI is evident in many ways. For example, a river usually flows at a certain speed, while a lake is generally still. Compared with the heat absorbed by a river flowing downstream, the processes of heat absorption and emission from a lake's surface occur at nearly the same site. In addition, a lake usually occupies a larger area than a river in a specific block area of a city. As evaporation causes heat absorption from the ambient environment, it leads to a drop of the lake's surface temperature. Therefore, a lake may have a greater potential to moderate the UHI effect than a river in a city. In the planning and design of an urban lake, the designer should therefore not only pay attention to landscape forms and landscape aesthetics but also put more focus on their design's effect on the urban thermal environment, especially the landscape surface effect. Different landscape surfaces have different abilities to reduce the UHI effect. Vegetation and trees can provide shading and cooling through evapotranspiration, as the solar radiation intensity in tree shade is nearly 
$10 \%$ of the radiation in the open air (Givoni et al., 2003). Conversely, an artificial surface, such as concrete and asphalt, absorbs more heat during the day and release it into the ambient environment, resulting in an increase in the ambient temperature. Therefore, the planner and designer should put some emphasis on the rationality of the land cover.

Although the work discussed above has shown the effectiveness of urban water bodies in mitigating the UHI, the research does not give direct evidence of lowering the ambient temperature in a complex surrounding environment. Furthermore, the efforts of previous researchers are concentrated on how water bodies affect the variation of the surrounding air temperature through evaporation. They do not consider the effect of land cover on the lakeshore and the propagation of cooling from the lake into the ambient environment. Thus, a study evaluating the microclimate effect of a lake on moderating the UHI is necessary. This study will focus specifically on the urban lake because a natural lake or an artificial lake can provide many ecological benefits; it can store fresh water and clean water, recharge groundwater, protect biological diversity, control flooding, and regulate climate (Han, 2006). Thus, the functions of climate regulation that arise from an urban lake should be considered by the urban planner and designer. Meanwhile, it is important to provide the evidence of the potential that urban lakes have to lower air temperature and the extent to which different adjacent land covers affect and propagate cooling. The objectives of this study include (1) providing the evidence for cooling air temperature on the surrounding lakeshore; (2) verifying the effect of different land covers of the surrounding lakeshore on lowering air temperature; and (3) determining the cooling effects at different distances from the different banks of the lake.

\section{Methods}

\section{Study area}

The study area is situated in Daming lake Park, Jinan, China. Daming lake is a natural lake and the largest lake in Jinan city. The park covers 104 ha, including the water surface area (58 ha) and the land area (46 ha). This lake is shallow, ranging in depth from $1 \mathrm{~m}$ to $3.5 \mathrm{~m}$ (Wang et al., 2010). The water of four springs converges in the lake through three main water inlets that are situated at the southeast, south, and west bank of the lake. The lake water flows into the Xiaoqing River from the northern water gate and a water outlet. The lakeshore is fringed with shrubs, trees and grass on the ring shape of the lake, and the paved road and the bridges are the main connections between pavilions, the ancestral hall, and other buildings (Fig. la,b). The temperature difference, which resulted from the UHI of Jinan city, reached approximately $0.56^{\circ} \mathrm{C}$ during the day and nearly $2^{\circ} \mathrm{C}$ at night in July 2007, whereas the difference rose to nearly $1{ }^{\circ} \mathrm{C}$ during the daytime and up to $2.74^{\circ} \mathrm{C}$ at night-time in October 2007 (Ran et al., 2010).

\section{Description of measurement sites}

Three automatic urban weather stations (UWS1, UWS2 and UWS3) were selected to evaluate the cooling effect of the waterfront of Daming lake. All of the UWS surrounding the study area were situated on the second ring road in the city. The maximum distance from a UWS to the centre of Daming lake was $2.5 \mathrm{~km}$, and the minimum distance was $1.4 \mathrm{~km}$ (Fig. 2). The GPS coordinates of three UWS are shown in Table 1. The sites of the UWS were in built-up areas. Two of them were located in the open square, where the UWS instrument (ZQZ-A, Suzhou, China) was installed adjacent to several trees at a 
height of $1.5 \mathrm{~m}$ above the grass lawn. The weather data provided by the instruments included air temperature, relative humidity, atmospheric pressure, wind speed, wind direction, and precipitation. The other UWS was sited on the green roof of a 5-storey building. Its instrument (ZQZ-A, Suzhou, China) was installed at the same height above the green roof to monitor air temperature and precipitation. Weather data were recorded hourly when the instrument worked properly. Additionally, all of the instruments were calibrated every year. Because the altitudes of the three sites were from $36.8 \mathrm{~m}$ to $39.0 \mathrm{~m}$, and the altitude of the Daming lake water surface is $23.9 \mathrm{~m}$, the height difference between the three UWS sites and Daming lake was too slight to take into account a lapse rate.
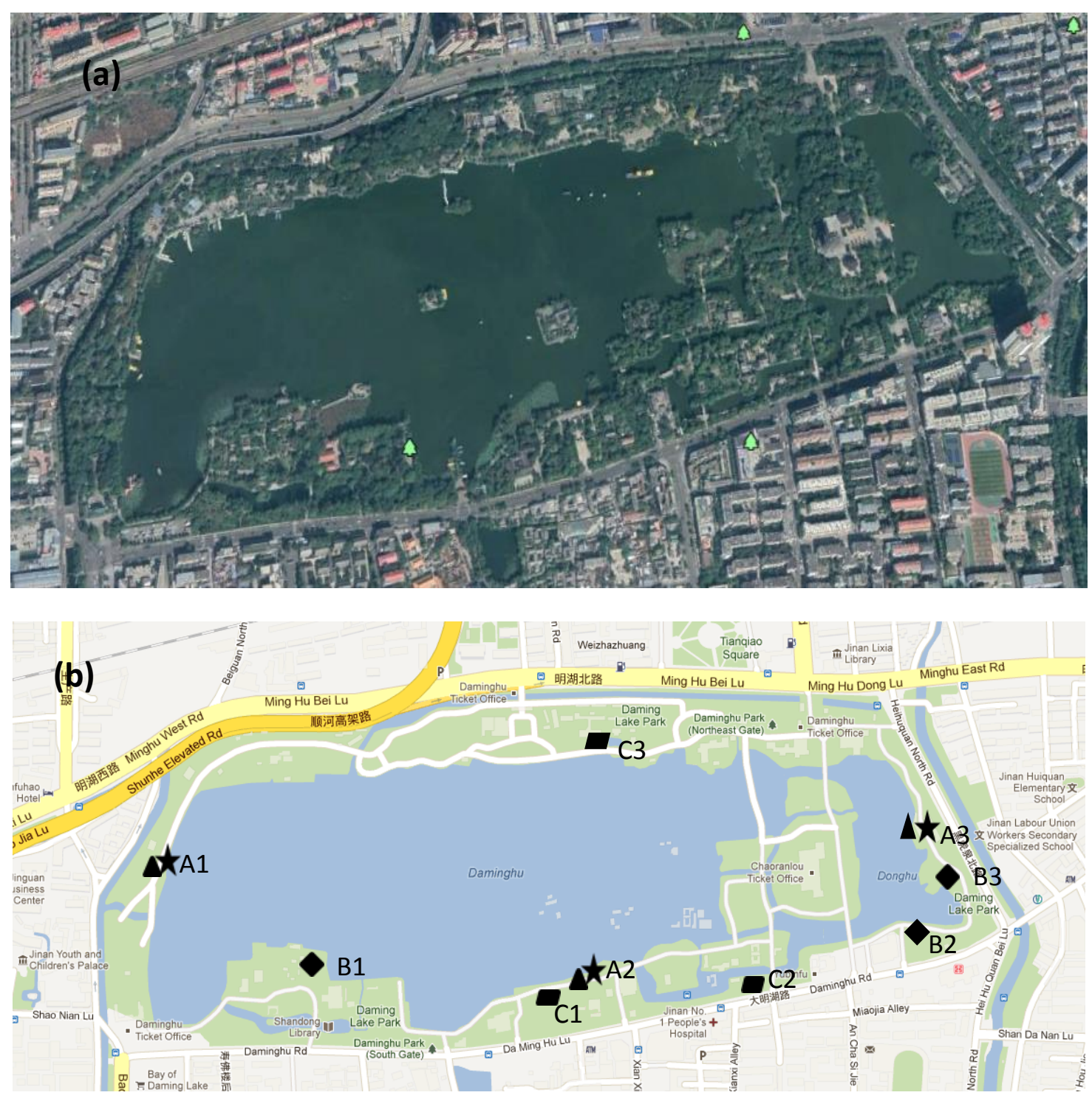

Figure 1. Remote sensing image (a) and map (b) of Daming Lake (Map source: Google maps).

$\boldsymbol{\Delta}$ a triangle represents the location of a measurement site

* a pentagram represents the lakeshore area covered by vegetation

a diamond represents the lakeshore area occupied by permeable paving

- a parallelogram represents the lakeshore area occupied by impermeable paving 


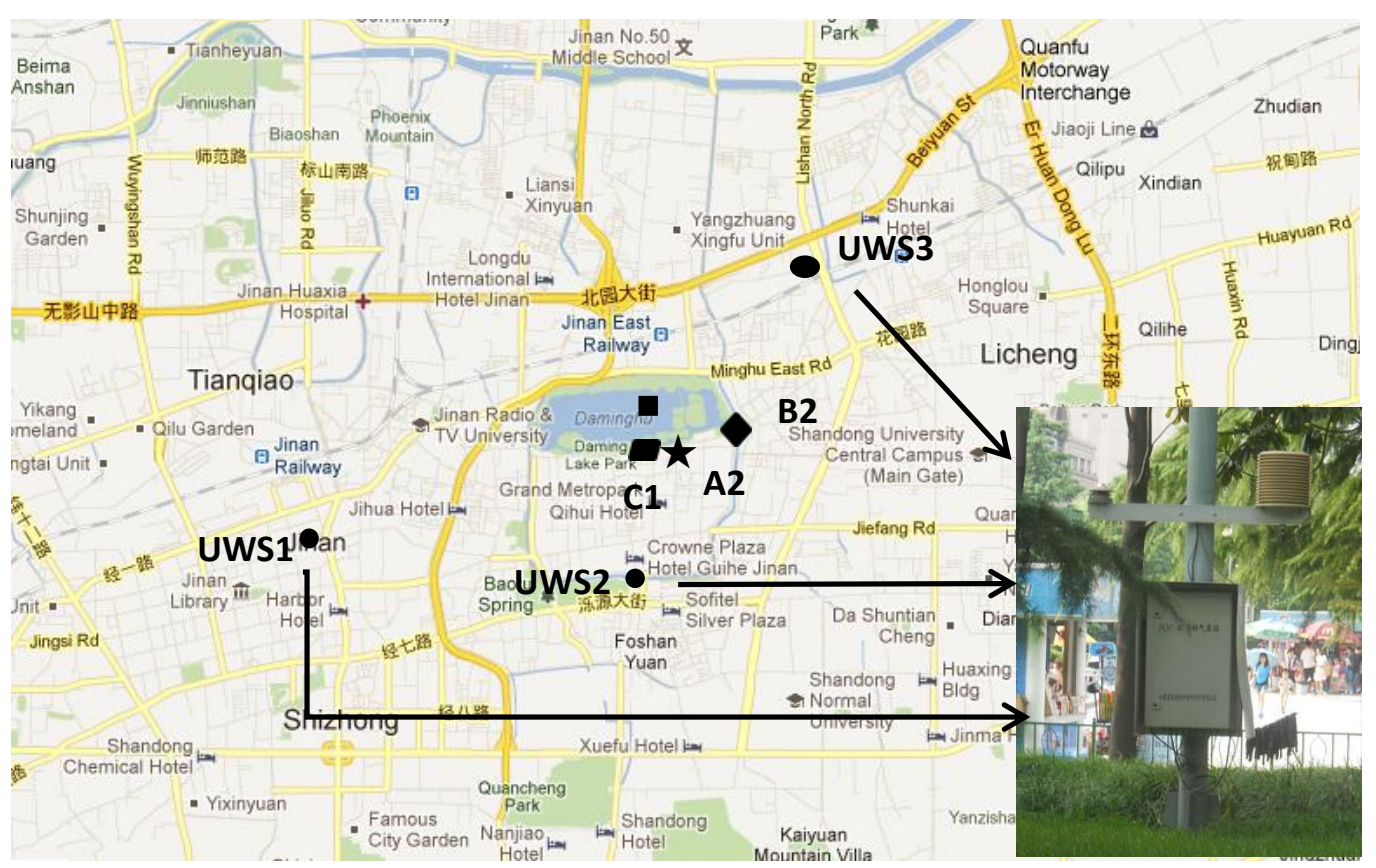

Figure 2. Locations of weather stations and Daming Lake in Jinan City (Map source:

Google maps).

a square represents the location of Daming lake

* represents the lakeshore A2 covered by vegetation

represents the lakeshore $C 1$ occupied by impermeable paving

represents the lakeshore $B 2$ occupied by permeable paving

- represents the location of an automatic weather station

Table 1. Measure sites and GPS coordinates in study area

\begin{tabular}{c|c|c|c|c|c}
\hline \multirow{2}{*}{ Sample Name } & \multicolumn{2}{|c|}{ GPS coordinates } & \multirow{2}{*}{ Sample Name } & \multicolumn{2}{c}{ GPS coordinates } \\
\cline { 2 - 3 } & Latitude & Longitude & & Latitude & Longitude \\
\hline UWS1 & $36.664522^{\circ}$ & $116.993835^{\circ}$ & B1 & $36.672819^{\circ}$ & $117.016575^{\circ}$ \\
UWS2 & $36.660341^{\circ}$ & $117.015332^{\circ}$ & B2 & $36.673743^{\circ}$ & $117.028641^{\circ}$ \\
UWS3 & $36.687529^{\circ}$ & $117.942916^{\circ}$ & B3 & $36.674896^{\circ}$ & $117.029581^{\circ}$ \\
A1 & $36.674946^{\circ}$ & $117.011271^{\circ}$ & C1 & $36.672806^{\circ}$ & $117.019918^{\circ}$ \\
A2 & $36.672953^{\circ}$ & $117.020875^{\circ}$ & C2 & $36.672504^{\circ}$ & $117.024482^{\circ}$ \\
A3 & $36.675917^{\circ}$ & $117.028288^{\circ}$ & C3 & $36.677002^{\circ}$ & $117.020313^{\circ}$ \\
\hline
\end{tabular}

To assess the cooling effect of the lake, three sites (Fig. 1) on Daming lake located at the west, south and east bank of the lake were chosen. The conditions of the three measurement sites were similar to those at the UWS in all respects. The GPS coordinates of measure sites are shown in Table 1. A type of measurement sites was adjacent to several trees that had some grass and shrub cover. Images of the sites are shown in Fig. 3-A2, land surface of $\mathrm{B}$ type is permeable, and $\mathrm{C}$ type is impermeable. Their images are also shown in Fig. 3-B2 and Fig. 3-C1, respectively.

To estimate the propagation of the cooling effect from the lakeshore to the ambient environment, nine research sites composed of three types of land covers were selected. These land covers (Fig. 3) included (1) vegetation, mainly covered by green grass and 
shrubs; (2) permeable paving, paved by holey concrete brick; and (3) impermeable paving, constructed by impermeable concrete brick. Site A1 was located on the western lakeshore, where concrete brick was paved at a distance of 1-2 m from the lake bank. Green grass and shrubs were planted adjacent to the brick far from the lakeshore; the planted area was approximately $20 \mathrm{~m} \times 30 \mathrm{~m}$. Sites A2 and A3 were similar in all respects, with green grass, shrubs and trees planted at a distance of approximately $30 \mathrm{~m}$ from the lakeshore. A concrete road approximately $3 \mathrm{~m}$ wide passes through the green area at a distance of approximately $15 \mathrm{~m}$ from the lakeshore. Sites B1 and B2 were smaller scale areas of approximately $15 \mathrm{~m} \times 20 \mathrm{~m}$, with willows and other trees at heights of approximately $4 \mathrm{~m}$ around them. For site B3, its scale is smaller than that of the two sites $\mathrm{B} 1$ and B2, occupying an area of approximately $4 \mathrm{~m} \times 15 \mathrm{~m}$ with trees and shrubs surrounding it. Sites C1, C2 and C3 were adjacent to the lakeshore. Site C1 was located at the southern gate of Daming lake; it was an open square with a decorated archway and several trees. Site $\mathrm{C} 2$ was located at an open place with an area of approximately $30 \mathrm{~m} \times 20 \mathrm{~m}$. Site C3 was located at the north bank of the lake, was fringed with several trees, and contained impermeable concrete brick extending to approximately $30 \mathrm{~m}$ from the waterfront.

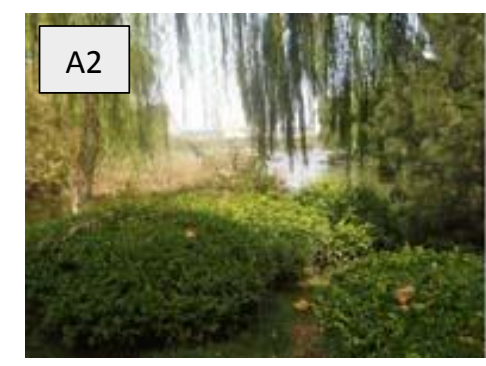

Figure 3. Images of every site type: a) vegetational site, b) permeable site, and c) impermeable site

\section{Survey methods}

Measurements of air temperature, water temperature and relative humidity were conducted from July to October in 2012, survey times of air temperature and water temperature at the lakeshore focused on 9:00-21:00, and the time of measurement at different lakeshore forms was from 10:00 to 22:00. Measurements of air temperature and water temperature were taken with mercury thermometers (Wuqiang Thermometer Company, Hengshui, China). This thermometer has an accuracy of $\pm 0.1^{\circ} \mathrm{C}$ between $0^{\circ} \mathrm{C}$ and $50^{\circ} \mathrm{C}$ and a resolution of $0.1^{\circ} \mathrm{C}$. All of the instruments were calibrated before the surveying period. Measurement campaigns were carried out in the periods of $21-26^{\text {th }} \mathrm{July}$, 15-17 ${ }^{\text {th }}$ August, 13-16 ${ }^{\text {th }}$ September and 13-18 ${ }^{\text {th }}$ October. In the course of temperature measurement, mercury thermometers were shielded with a simple instrument shelter. Air temperature at the lakeshore was recorded 4 times per day (9:00, 13:00, 17:00, and 21:00), and surveying campaigns at different lakeshore forms were performed 4 times per day $(10: 00,14: 00,18: 00$ and 22:00) at $10 \mathrm{~m}$ intervals from the lake edge to $40 \mathrm{~m}$ away. Water temperature was measured hourly from 9:00 to 21:00. When the surveyor stood at the bank, the mercury thermometer was placed $0.1 \mathrm{~m}$ vertically below the water surface. During September and October in Jinan, the prevailing winds were mostly from the northwest to west directions. Wind speed usually ranged from 0 to $3 \mathrm{~m} / \mathrm{s}$, so special days 
in autumn were chosen when wind speed slowed below $1.0 \mathrm{~m} / \mathrm{s}$. For evaluating the role of the lake water body and lakeshore form in mitigating the UHI, the surveyor spent more than two minutes to accurately measure temperature at every site. The measurement location was $1.5 \mathrm{~m}$ above the ground.

The paired-samples $T$-test was applied for a significance level $\alpha=0.05$. Thus, if a $p$-value was computed to be less than 0.05 , then the temperature difference would be considered statistically significant. The statistical significance $(p), t$-statistic $(t)$, and degrees of freedom $(d f)$ are found in the latter data analysis. The effect size $(r)$ based on Pearson's correlation is used to measure the strength of the relationship between measuring the lakeshore air temperature and the UWS's.

\section{Results}

\section{Role of the urban lake in mitigating the UHI}

Part of the purpose of this paper is to assess the cooling effect of the lake, and therefore, we chose the study period between $21^{\text {st }}$ July and $18^{\text {th }}$ October. To estimate the temperature difference between the urban weather stations and the lakeshore, the measuring sites were selected for their vegetation cover. As such, the measuring conditions of urban weather stations (UWS1, UWS2 and UWS3) were similar to that of the lakeshore. The sites of the lakeshore are referred to as A1, A2 and A3, and the temperature differences between the urban weather stations and the lakeshore based on the measurement periods are calculated using:

$$
\Delta T_{i}=T_{i}-T_{U W S}
$$

where $T_{U W S}$ is the mean temperature from the three urban weather stations, the index $i$ is the reference for the individual lakeshore (A1, A2 or A3), and $T_{i}$ is the arithmetical mean value of the monitoring data at the same measuring time for every monitoring period. A negative value of $\Delta T_{i}$ indicates cooling adjacent to the lake in comparison to the urban weather stations. Fig. $4 a-d$ shows the value of $\Delta T_{i}$ for different time periods at different sites adjacent to the lake. All of the monitored air temperatures are lower than the air temperature at the urban weather stations.

The air temperature varied from $22.7^{\circ} \mathrm{C}$ to $30.9^{\circ} \mathrm{C}$ during the measuring period in July and varied from $23.1^{\circ} \mathrm{C}$ to $31.7^{\circ} \mathrm{C}$ in August, compared with a variation from $17.8^{\circ} \mathrm{C}$ to $27.6^{\circ} \mathrm{C}$ in September and from $14.1^{\circ} \mathrm{C}$ to $20.1^{\circ} \mathrm{C}$ in October. The temperature difference at different measuring times for one day in July and August is illustrated in Fig. 4a-b. During most hours of the day, it was lightly cloudy and the wind velocity varied from $0.3 \mathrm{~ms}^{-1}$ to $0.7 \mathrm{~ms}^{-1}$. Analysing the temperature differences at different times, the mean of temperature difference was $1.0^{\circ} \mathrm{C}$ and $1.2^{\circ} \mathrm{C}$, respectively. The cooling effect was more significant in August than July. At the same time, the highest temperature difference at 9:00 was approximately equal between July $\left(-1.9\right.$ to $\left.-1.1^{\circ} \mathrm{C}\right)$ and August $\left(-1.8\right.$ to $\left.-1.1^{\circ} \mathrm{C}\right)$, and the lowest temperature at 21:00 in July was -0.7 to $-0.3^{\circ} \mathrm{C}$, compared with August $\left(-0.6\right.$ to $\left.-0.4^{\circ} \mathrm{C}\right)$. Furthermore, temperature differences were also influenced by the measuring location in two periods: in July, the lowest temperature difference was recorded at site $\mathrm{A} 2$, where the mean of the temperature difference was $0.7^{\circ} \mathrm{C}$, and the highest temperature difference was recorded at site $\mathrm{A} 1$, where the mean of the temperature difference reached $1.2^{\circ} \mathrm{C}$. The paired-samples T-test result shows the value 
of $t, d f, p$ and $r, t(119)=3.50, p<0.05$, and $r=0.81$. Similarly, in August, the level of cooling is lowest at site $\mathrm{A} 2$, where the mean of the temperature difference is $0.8^{\circ} \mathrm{C}$, while site A1 presents the highest level of cooling, where the mean of the temperature difference is $1.2^{\circ} \mathrm{C}(t(119)=3.49, p<0.05, r=0.74)$.
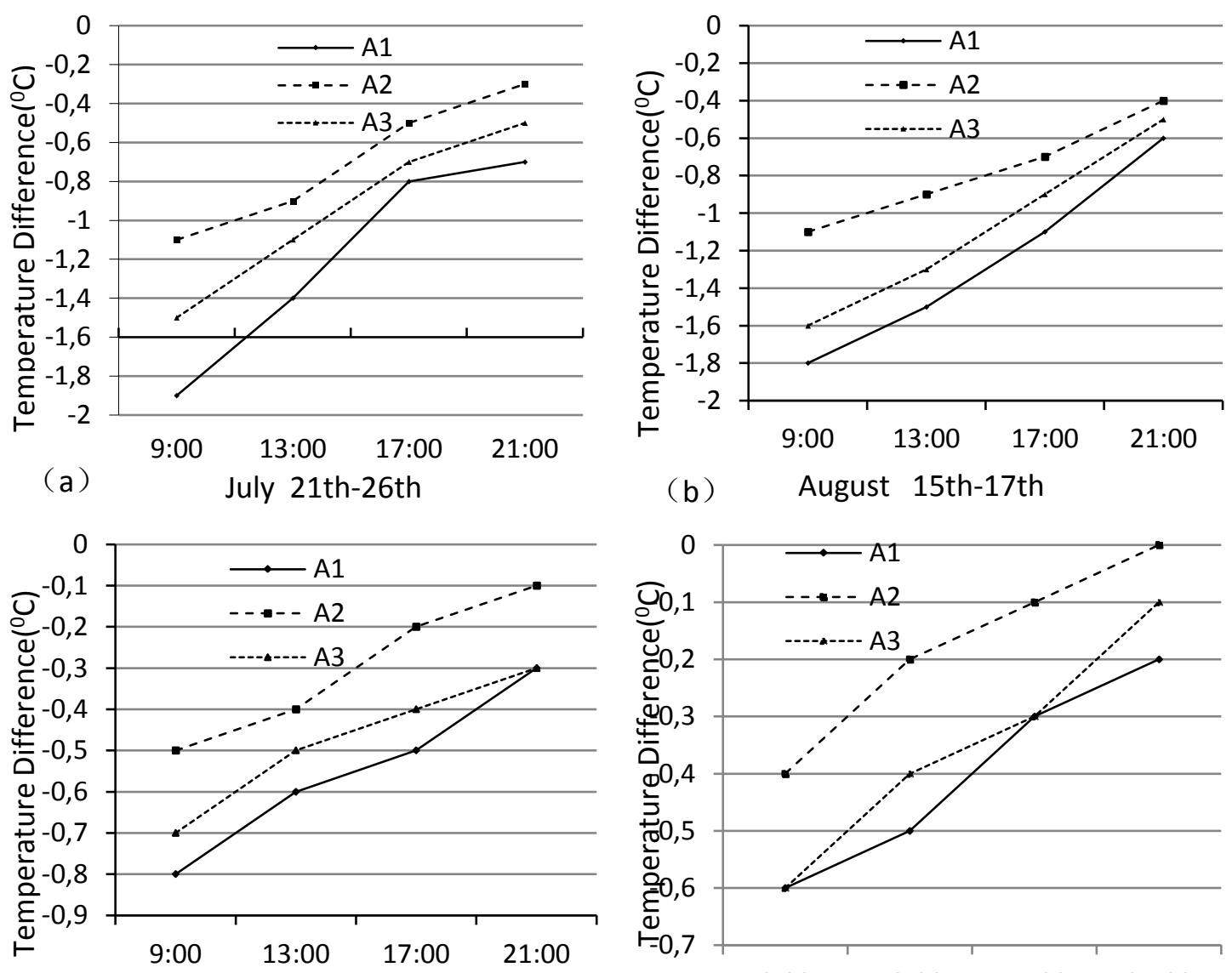

(c) September 13th-16th

(b) August 15th-17th



Figure 4. Temperature differences for different sites at different periods, $\Delta T$ is the mean of the temperature differences in each measuring period

Fig. $4 c$ - $d$ shows the temperature difference at different measuring times for one day in September and October. Calm conditions $\left(0.4-1.0 \mathrm{~ms}^{-1}\right)$ were encountered in the two monitoring sessions, and light cloudiness was observed for the two periods. Likewise, the variation of the temperature difference is similar to that discussed above, so similar conclusions can be derived from the two periods. However, the mean of the temperature difference is $0.4^{\circ} \mathrm{C}$ and $0.3^{\circ} \mathrm{C}$, respectively, in September and October, so the cooling effect is less significant in these two periods than in the former two. The highest temperature difference arises at 9:00 $\left(-0.8\right.$ to $-0.5^{\circ} \mathrm{C}$ and 0.6 to $0.4^{\circ} \mathrm{C}$ in September and October, respectively) and the lowest at $21: 00\left(-0.3\right.$ to $-0.1{ }^{\circ} \mathrm{C}$ and $\left.0.2-0^{\circ} \mathrm{C}\right)$. In September, the lowest temperature difference also arises at site $\mathrm{A} 2$, where the mean of the temperature difference is just $0.3^{\circ} \mathrm{C}$, and the highest temperature difference is at site $\mathrm{A} 1$, where the mean of the temperature difference reached $0.6^{\circ} \mathrm{C}(t(119)=2.07, p<0.05, r=0.89)$. In October, the lowest temperature difference is recorded at site A2, where the mean of the 
temperature difference is $0.2^{\circ} \mathrm{C}$, and the highest temperature difference is calculated at $\mathrm{A} 1$, where the mean of the temperature difference is up to $0.4^{\circ} \mathrm{C}(t(119)=1.12, p>0.05$, $r=0.90)$.

The average temperature difference is calculated from the measured data from the three lakeside measurement points (A1, A2 and A3) at 4 different times per day during the study period. The temperature difference between the lakeside sites and the urban weather stations for different observation times is illustrated in Fig. 5.

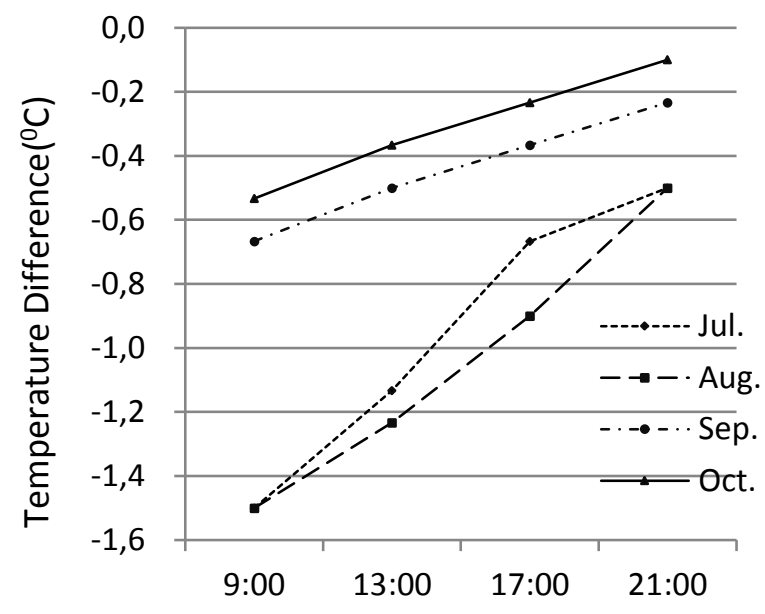

Figure 5. Temperature differences at different time periods; $\Delta T$ is the mean of the temperature differences at the measuring times in each month

The cooling effect is more significant in July and August than in September and October. The highest levels of cooling are shown in August, and the level of cooling in July is close to that in August, wherein the mean temperature difference is just $0.2^{\circ} \mathrm{C}$ lower in August than July. Likewise, the cooling effect is no more significant in September than in October. The mean temperature difference is just $0.1^{\circ} \mathrm{C}$ lower in September than in October.

The paired-samples T-test is applied to determine if temperature differences are significant among the four month. In terms of the statistics, the $p$ value between July and August is 0.922 , which is greater than the $\alpha$ level $(\alpha=0.05)$, so we fail to reject $H_{0}$. That is, there is insufficient evidence to claim that the temperature difference may be different from each other in the two month. Similarly, the statistical results show that the temperature differences are insignificant in September and October. However, the statistical result suggests that the temperature difference between August and September is significant, where the $\mathrm{p}$ value is less than 0.05 . The full statistical results are shown in Table 2.

Table 2. The paired-samples T-test for paired comparisons from July to October

\begin{tabular}{c|c|c|c|c|c}
\hline Pair & M & Std. D & t & df & P \\
\hline Jul. - Aug. & 0.04 & 3.90 & 0.10 & 119 & 0.92 \\
Aug. -Sep. & -0.55 & 3.10 & -1.93 & 119 & 0.05 \\
Sep. - Oct. & -0.14 & 2.14 & -0.70 & 119 & 0.48 \\
\hline
\end{tabular}

$\mathrm{M}$ is for the temperature difference between the two months. Also shown is the standard deviation (Std.

$D)$, the $t$ statistic $(t)$, the degrees of freedom (df), and the two-tailed significance $(P)$ 


\section{Effect of different lakeshore forms on the UHI}

The cooling from the lake varies with the different forms of the lake bank, as illustrated in Fig. 6, with greater cooling found at the vegetated site and with less cooling at the impermeable site. Furthermore, a higher ambient air temperature contributes to greater cooling from July to October. The air temperature is higher in August than in the other measuring months, and the cooling effect is the most significant. Three type of urban forms ( $\mathrm{A}$ is a vegetated site, $\mathrm{B}$ is a permeable site and $\mathrm{C}$ is an impermeable site) are adjacent to the lakeshore. At the A sites in August, the mean temperature difference reached $1.6^{\circ} \mathrm{C}$ at $10: 00$. At the same time, the average temperature difference was just $0.8^{\circ} \mathrm{C}$ and $0.6^{\circ} \mathrm{C}$, respectively, at the B sites and C sites. Moreover, the level of cooling fell from 10:00 to 22:00. Similarly, a difference in the cooling effect derived from the different lakeshore forms was found in the other measuring months, but the difference of cooling was insignificant between B and C. By October, the difference of $0.03^{\circ} \mathrm{C}$ between $\mathrm{B}$ and $\mathrm{C}$ is negligible.
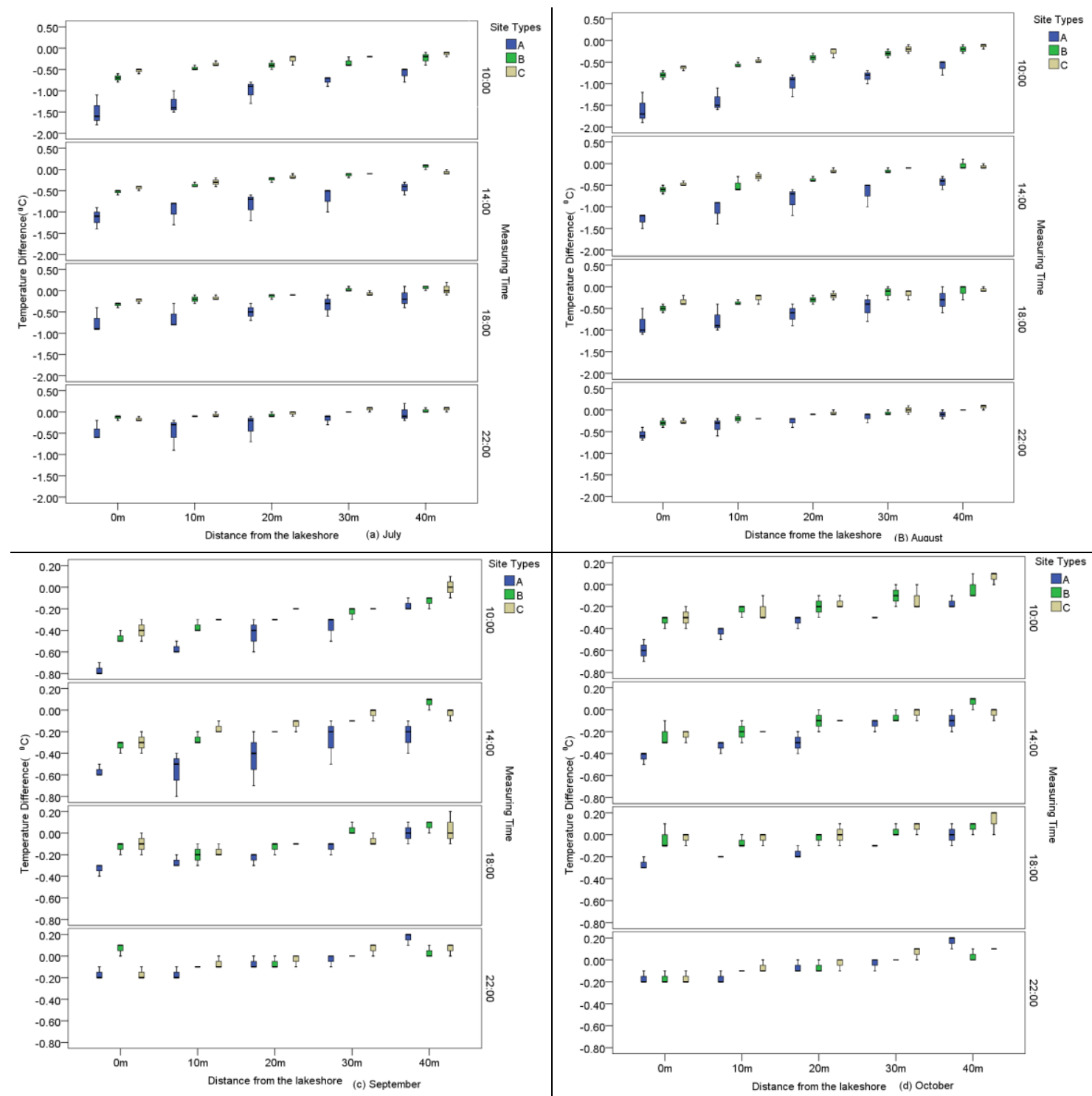

Figure 6. Temperature differences at different distances from July to October, A represents the vegetated site, $B$ represents the permeable site, and $C$ represents the impermeable site 


\section{Effect of distance from the water body on the UHI}

The distance from the lake bank has significant effects on cooling. Fig. 6 presents the variation in cooling across the different distances. Longer distances from the lakeshore are responsible for less cooling from July to October. At all measuring sites, the level of cooling $40 \mathrm{~m}$ from the lakeshore is less than $0.6^{\circ} \mathrm{C}$, and there is little variation depending on the form of the lake bank in warmer months. For example, the temperature difference of $\mathrm{A}, \mathrm{B}$ and $\mathrm{C}$ is just $0.6^{\circ} \mathrm{C}, 0.2^{\circ} \mathrm{C}$ and $0.1^{\circ} \mathrm{C}$, respectively, at $10: 00$ in August. However, the variation caused by lakeshore land cover can be ignored at 22:00 in October because each of the temperature differences of the three land covers is close to $0^{\circ} \mathrm{C}$. Overall, the results indicate that vegetated sites next to the lake bank increase the cooling level. That is, the cooling effect is more significant at $\mathrm{A}$ sites than at $\mathrm{B}$ and $\mathrm{C}$ sites. Fig. $6 a-d$ shows the average $\Delta T$ for each measuring time when combining the four periods, with values shown separately for the sites from $0 \mathrm{~m}$ to $40 \mathrm{~m}$ adjacent to the lakeshore. Very high levels of cooling are shown at the sites adjacent to the lakeshore, which reduce moving away from the lakeshore. The same trend of a cooling drop is observed from the morning to the night.

\section{Discussion}

\section{Effect of the water body on cooling}

Site A1 was located on the western lakeshore. Because concrete brick was paved at a distance of 1-2 $\mathrm{m}$ from the lake bank and the measuring location was $1.5 \mathrm{~m}$ above the water body adjacent to the lakeshore, there was no vegetation on the ground below the measuring location. Both site A2 and site A3 were also adjacent to the water body, and the measuring conditions of the two sites were similar to each other. The two measuring location were also $1.5 \mathrm{~m}$ above the water surface, but each of the grounds below the two measuring locations was filled with vegetation. The results above show that the cooling effect at A1 is more significant than that at the other two sites. However, the fact that vegetated land cover relieves urban heat is well known, so the result above also shows that the vegetated lakeshore form (A type) plays a greater role in lowering air temperature compared with the permeable sites and the impermeable sites. Why is the cooling effect at A1 the most significant? At the same time, the level of cooling is more significant at site A3 than at site A2. The difference in the cooling effect among the three measuring sites may relate to water temperature. Analysing the data on water temperature, the water temperatures at site A1 and site A3 are lower than that at site A2, especially in the early morning. In fact, cool spring water flows into the inlets of the lake, and A2 is further away from the water inlet compared with A1 and A3. Fig. 7 shows the variation of the average water temperature at $\mathrm{A} 1, \mathrm{~A} 2$ and $\mathrm{A} 3$ in August. Water temperature increases from 9:00 to $16: 00$, and it then declines in the latter measuring time intervals. The difference between the air temperature at the UWS and the water temperature rises from 9:00 to 13:00, and it then falls continually. The variation of the difference is out of sync with the cooling level, which suggests that other factors are also responsible for the cooling level.

\section{Effect of climatic condition on cooling}

Under the conditions of the same temperature interval, the level of cooling in July and August is more significant than that in September and October. Furthermore, there is a distinct cooling difference at different measuring times of the same month. Fig. 8 shows 
the variation of temperature differences in similar temperature conditions. The air temperature varied from 14.1 to $31.7^{\circ} \mathrm{C}$ in the whole research period. With the maximum temperature difference of nearly $18^{\circ} \mathrm{C}$, the interval of $2^{\circ} \mathrm{C}$ is chosen in the statistical analysis. In the interval of $14-16^{\circ} \mathrm{C}$, the mean of the air temperature at both 9:00 and 21:00 in October belongs to this interval, but the cooling effect at the two measuring times differs from 0.5 to $0.1^{\circ} \mathrm{C}$. Furthermore, the difference in the cooling effect from 9:00 in July and 9:00 in August to 21:00 in July and 13:00 in September is more significant, from 1.5 to $0.5^{\circ} \mathrm{C}$. However, the contribution to cooling at 21:00 in September and 17:00 in October is approximately equivalent in the interval of $16-18^{\circ} \mathrm{C}$. Similar results are found at 13:00 in July and August in the interval of $30-32^{\circ} \mathrm{C}$. These analyses suggest that other factors aside from the air temperature, such as solar light intensity, wind speed and water temperature, may have great influences on cooling. Research over the past two decades has shown significant correlations between temperature difference and these factors (Hathway and Sharples, 2012; Zhao et al., 2014; Li et al., 2014).

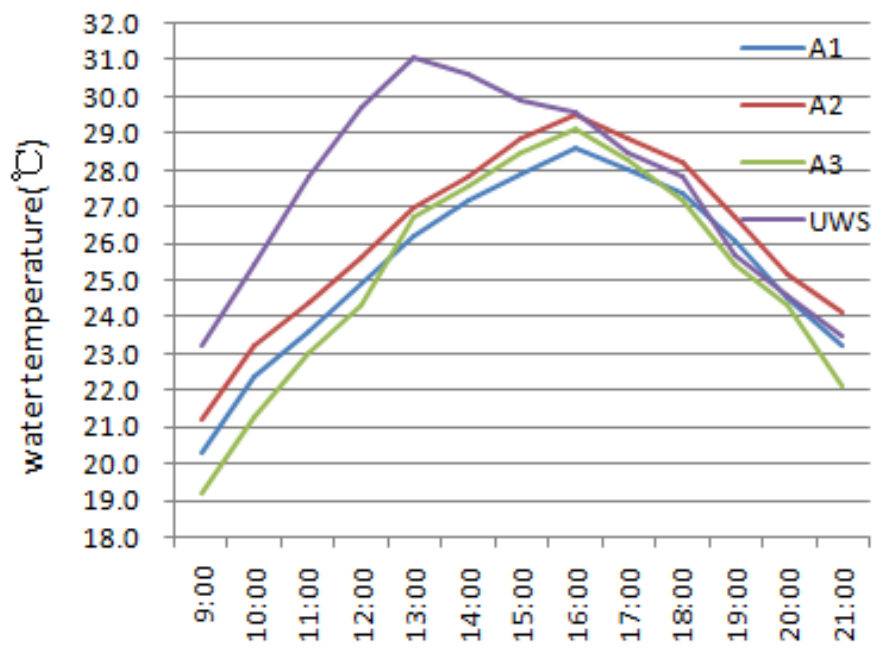

Figure 7. Variation of the average water temperature at A1, A2 and A3 in August compared with the average air temperature of the UWS

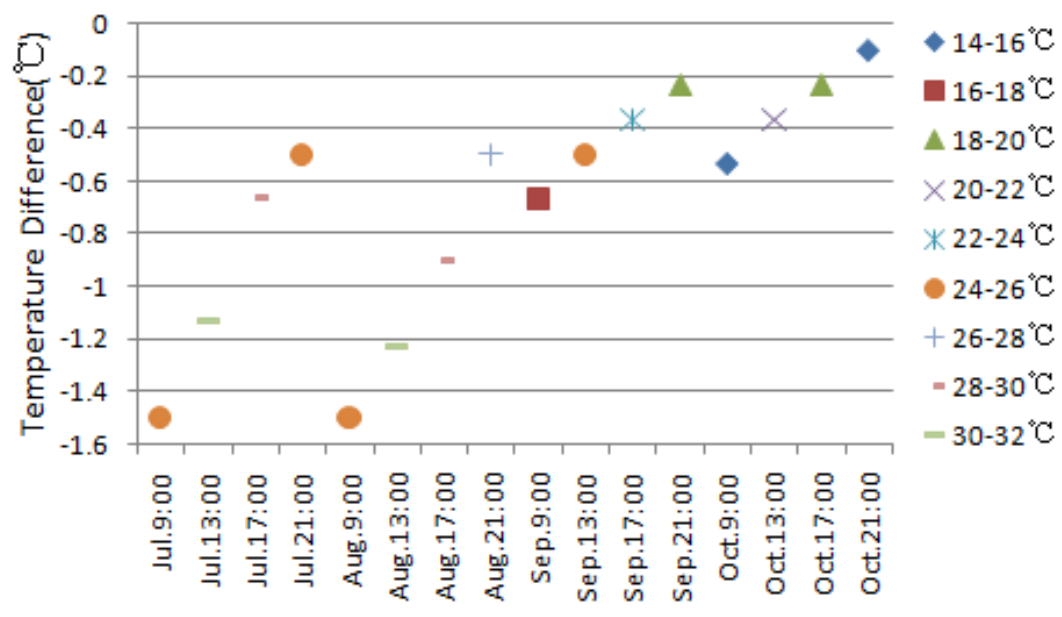

Figure 8. The comparison of the temperature difference at different times during the entire study period. The right legend symbols represent different temperature conditions 


\section{Advantages and limitations of the study}

Numerous research have examined cooling effect of water bodies on the urban heat islands. this study employed the data from meteorological stations and field observation to evaluate the role of water bodies to mitigate urban heat islands during the two seasons. Hathway and Sharples (2012) found the cool island effect becomes more obvious during a spring/summer period as the temperature rose, and this conclusion was consistent with this paper and $\mathrm{Xu}$ et al. (2010), but we found that landscape type near lakeshore had different impact on cooling effect. Compared with data from meteorological stations and field observation, remote sensing images can provide more information on land use as well as retrieve land surface temperatures in larger areas. Many literature have showed the water bodies and adjacent landscape forms have important effect on land surface temperatures (Weng, 2009; Sun and Chen, 2012; Li et al., 2013; Kong et al., 2014; Cai et al., 2018). Although remote sensing images can retrieve land surface temperatures on a large scale, remote sensing images obtained are at a fixed time at a certain interval. In future studies, we will use field observation and remote sensing data to combine to analyse the cooling effect of water bodies.

\section{Conclusions}

In this study in Jinan, the statistical results show, first, that the urban lake plays a considerable role on cooling the air temperature around the lake bank. Second, the lakeshore type and distance from the lake bank have a significant effect on the level of cooling.

The analytic results reveal significant cooling adjacent to the lakeshore, with an average cooling of nearly $1^{\circ} \mathrm{C}$ from July to August. Following the drop in air temperature, the effect of cooling increasingly weakened, and the level of cooling of $0.3^{\circ} \mathrm{C}$ in October was less significant than that in July and August. The average temperature difference of the entire period tended to reach the maximum in the mornings, with cooling at the lake bank varying from $1.9^{\circ} \mathrm{C}$ to $0.4^{\circ} \mathrm{C}$ depending on the different lakeshore types and different months. Furthermore, the level of cooling declined from 9:00 to 21:00 each day. The results also show that highly vegetated lakeshores play a more significant role on cooling air temperatures than those lakeshores consisting of permeable or impermeable materials. Therefore, in the planning and design of an urban lake, the designers should not only focus on landscape forms and landscape aesthetics but also pay more attention to their effect on the urban thermal environment, especially the landscape surface effect. However, the results of this research were based on measurement data from only one urban lake for two seasons, and the research was conducted for only one metropolitan area. Future studies across metropolitan areas under different climatic conditions that combine measurement data with thermal infrared imaging would be desirable to confirm and refine these findings.

Acknowledgements. This work was funded by the National Natural Science Foundation of China (Project Number 41271116) and the Public Science Research Program of Surveying, Mapping and Geoinformation (Project Number 201412016). The authors would like to thank the editor and the anonymous reviewers for their helpful comments and suggestions. 


\section{REFERENCES}

[1] Cai, Z., Han, G., Chen, M. (2018): Do water bodies play an important role in the relationship between urban form and land surface temperature? - Sustainable Cities and Society 39: 487-498.

[2] Chang, C. R., Li, M. H., Chang, S. D. (2007): A preliminary study on the local cool-island intensity of Taipei city parks. - Landscape and Urban Planning 80: 386-395.

[3] Dai, Z., Guldmann, J. M., Hu, Y. (2019): Thermal impacts of greenery, water, and impervious structures in Beijing's Olympic area: A spatial regression approach. Ecological Indicators 97: 77-88.

[4] Ding, S., Cao, X. (2004): Landscape Pattern Dynamics of Water Body in Kaifeng City since the End of the Qing Dynasty (AD1898-2002). - Acta Geographica Sinica 59: 956-963.

[5] Du, H., Song, X., Jiang, H., Kan, Z., Wang, Z., Cai, Y. (2016): Research on the cooling island effects of water body: A case study of Shanghai, China. - Ecological Indicators 67: 31-38.

[6] Givoni, B., Noguchi, M., Saaroni, H., Pochter, O., Yaacov, Y., Feller, N., Becker, S. (2003): Outdoor comfort research issues. - Energy and Buildings 35: 77-86.

[7] Gober, P., Brazel, A., Quay, R., Myint, S., Grossman-Clarke, S., Miller, A., Rossi, S. (2009): Using Watered Landscapes to Manipulate Urban Heat Island Effects: How Much Water Will It Take to Cool Phoenix? - Journal of the American Planning Association 76: 109121.

[8] Grinzato, E., Bison, P. G., Marinetti, S. (2002): Monitoring of ancient buildings by the thermal method. - Journal of Cultural Heritage 3: 21-29.

[9] Guillevic, P. C., Biard, J. C., Hulley, G. C., Privette, J. L., Hook, S. J., Olioso, A., Göttsche, F. M., Radocinski, R., Román, M. O., Yu, Y., Csiszar, I. (2014): Validation of Land Surface Temperature products derived from the Visible Infrared Imaging Radiometer Suite (VIIRS) using ground-based and heritage satellite measurements. - Remote Sensing of Environment 154: 19-37.

[10] Gupta, N., Mathew, A., Khandelwal, S. (2019): Analysis of cooling effect of water bodies on land surface temperature in nearby region: A case study of Ahmedabad and Chandigarh cities in India. - The Egyptian Journal of Remote Sensing and Space Science 22: 81-93.

[11] Han, Z. (2006): Functions of urban lake and the effect of lake restoration on surrounding environment. - Environment 12-13.

[12] Hathway, E. A., Sharples, S. (2012): The interaction of rivers and urban form in mitigating the Urban Heat Island effect: A UK case study. - Building and Environment 58: 14-22.

[13] Kong, F., Yin, H., James, P., Hutyra, L. R., He, H. S. (2014): Effects of spatial pattern of greenspace on urban cooling in a large metropolitan area of eastern China. - Landscape and Urban Planning 128: 35-47.

[14] Li, D., Ai, B., Li, X. (2008): Urban Water Body Alleviating Heat Island Effect Based on RS and GIS: A Case Study of Dongguan City. - Tropical Geography 28: 414-418.

[15] Li, Z. L., Tang, B. H., Wu, H., Ren, H., Yan, G., Wan, Z., Trigo, I. F., Sobrino, J. A. (2013): Satellite-derived land surface temperature: Current status and perspectives. - Remote Sensing of Environment 131: 14-37.

[16] Li, D., Bou Zeid, E., Oppenheimer, M. (2014): The effectiveness of cool and green roofs as urban heat island mitigation strategies. - Environmental Research Letters 9: 16.

[17] Li, G., Zhang, X., Mirzaei, P. A., Zhang, J., Zhao, Z. (2018): Urban heat island effect of a typical valley city in China: Responds to the global warming and rapid urbanization. Sustainable Cities and Society 38: 736-745.

[18] Murakawa, S., Sekine, T., Narita, K.-i., Nishina, D. (1991): Study of the effects of a river on the thermal environment in an urban area. - Energy and Buildings 16: 993-1001.

[19] Oláh, A. B. (2012): The possibilities of decreasing the urban heat island. - Applied Ecology and Environmental Research 10: 173-183.

[20] Ran, G., Hu, P., Zhang, N., Chen, X., Hu, X. (2010): Analysis of Urban Heat Island Effect 
in Jinan. - Meteorological Science and Technology 38: 97-101.

[21] Rizwan, A. M., Dennis, L. Y. C., Liu, C. (2008): A review on the generation, determination and mitigation of Urban Heat Island. - Journal of Environmental Sciences 20: 120-128.

[22] Rosenfeld, A. H., Akbari, H., Bretz, S., Fishman, B. L., Kurn, D. M., Sailor, D., Taha, H. (1995): Mitigation of urban heat islands: materials, utility programs, updates. - Energy and Buildings 22: 255-265.

[23] Singh, P., Kikon, N., Verma, P. (2017): Impact of land use change and urbanization on urban heat island in Lucknow city, Central India. A remote sensing based estimate. - Sustainable Cities and Society 32: 100-114.

[24] Steeneveld, G. J., Koopmans, S., Heusinkveld, B. G., Theeuwes, N. E. (2014): Refreshing the role of open water surfaces on mitigating the maximum urban heat island effect. Landscape and Urban Planning 121: 92-96.

[25] Su, Y. F., Foody, G. M., Cheng, K.-S. (2012): Spatial non-stationarity in the relationships between land cover and surface temperature in an urban heat island and its impacts on thermally sensitive populations. - Landscape and Urban Planning 107: 172-180.

[26] Sun, R., Chen, L. (2012): How can urban water bodies be designed for climate adaptation? - Landscape and Urban Planning 105: 27-33.

[27] Unwin, D. J. (1980): The synoptic climatology of Birmingham's urban heat island, 196574. - Weather 35: 43-50.

[28] Wang, X., Wang, B., Li, X. (2010): Analysis and Assessment on Main Nutritious Elements from Inner and Exterior Contamination in Daming Lake. - Journal of University of Jinan (Science and Technology): 262-267.

[29] Weng, Q. (2009): Thermal infrared remote sensing for urban climate and environmental studies: Methods, applications, and trends. - ISPRS Journal of Photogrammetry and Remote Sensing 64: 335-344.

[30] Xu, J., Wei, Q., Huang, X., Zhu, X., Li, G. (2010): Evaluation of human thermal comfort near urban waterbody during summer. - Building and Environment 45: 1072-1080.

[31] Zhao, L., Lee, X., Smith, R. B., Oleson, K. (2014): Strong contributions of local background climate to urban heat islands. - Nature 511: 216-219. 